DR NICK J LEVELL (Orcid ID : 0000-0003-3393-8305)

Article type : Concise Report

\title{
Lower limb cellulitis: low diagnostic accuracy and underdiagnosis of risk factors
}

\author{
K. Mistry ${ }^{1}$, M Sutherland ${ }^{2}$, N. J. Levell ${ }^{1,2}$ \\ ${ }^{1}$ Norwich Medical School, University of East Anglia, Norwich, UK \\ ${ }^{2}$ Department of Dermatology, Norfolk and Norwich University Hospital, Norwich, UK
}

Funding: This research received no specific grant from any funding agency in the public, commercial, or not-for-profit sectors.

Conflicts of interest: KM and MS have no conflicts of interest. NJL is an officer of the British Association of Dermatologists charity, which owns the Clinical and Experimental Journal but has no influence on editorial policy.

Correspondence: Mr Khaylen Mistry

E-mail: Khaylen.Mistry@uea.ac.uk

This article has been accepted for publication and undergone full peer review but has not been through the copyediting, typesetting, pagination and proofreading process, which may lead to differences between this version and the Version of Record. Please cite this article as doi: $10.1111 /$ ced.13930

This article is protected by copyright. All rights reserved. 
Keywords: cellulitis, diagnosis, recurrence, risk factors

\section{Abstract}

Accurate diagnosis and recognition of predisposing factors has been shown to be challenging in lower limb cellulitis. Assessment of 1746 consecutive cellulitis patients presenting to a UK university hospital showed increasing overdiagnosis with only $31.9 \%$ of referred patients with confirmed lower-limb cellulitis between 2015-2018. Recognition of at least one predisposing factor increased from $61 \%$ to $89 \%$ following introduction of more specific screening questions. This identified a need for better primary care dermatology education and the benefit of a proforma with specific screening questions for reversible predisposing factors for lower limb cellulitis.

\section{Background}

Lower limb cellulitis is common and costly but may be inaccurately diagnosed with $30.5-33 \%$ of referred patients having other conditions ${ }^{1,2}$. This increases risk to patients and wastes resources by delayed diagnosis and prolonging inpatient treatment with unnecessary antibiotic use. Cellulitis inpatient costs in England (UK) were approximately $£ 226 \mathrm{~m}$ in $2017-18$ for 88,664 inpatients (NHS reference costs Skin Disorders without Interventions $£ 2,553)^{3,4}$.

Lower limb cellulitis risk factors include lymphoedema/chronic oedema, venous eczema, tinea pedis, trauma, leg ulcers and $\mathrm{BMI}>30 \mathrm{~kg} / \mathrm{m}^{25,6}$. Recurrence of lower-limb cellulitis is common, occurring in $37 \%$ within a year ${ }^{7}$ however the identification and treatment of modifiable risk factors may show promise in reducing recurrence rates.

This article is protected by copyright. All rights reserved. 
Norfolk and Norwich University Hospital (NNUH), in the East of England, established an innovative dermatology outpatient-based cellulitis service in 2007 to improve diagnosis and management of lower limb cellulitis. Patients were referred from other clinicians in primary and secondary care and assessed by dermatology specialist nurses and doctors, prior to treatment as outpatients initially with once daily IV Ceftrioxone ${ }^{1}$. Since set up eleven years ago, patients and specialist nurses completed a proforma to establish a database for audit purposes. This proforma was improved in January 2018 to include specific questions on cellulitis risk factors, rather than open questions. This is the world's largest reported series of 1746 consecutive patients referred from 2007 to July 2018 with possible lower limb cellulitis (as of 22/07/2018), with previous reported audits in 2010 and $2015^{1,8}$

In 2017, the Cellulitis Priority Setting Partnership prioritised research into the diagnosis and prevention of cellulitis ${ }^{9}$. Accurate diagnosis and identification of risk factors are essential for optimal patient care. Previous audits at NNUH identified inaccurate diagnosis and inadequate recognition of risk factors ${ }^{1,8}$, so these were re-audited in July 2018.

\section{Report}

373 patients presenting between $2015-2018$ were analysed with 53/373 patients seen after the introduction of specific predisposing factor questions to the proforma.

119 (31.9\%) of the 373 patients referred to the service in $2015-18$ were confirmed to have cellulitis. Other diagnosis included 82 (22\%) patients with venous eczema, 37 (10\%) patients with chronic oedema and 34 (9\%) patients with lymphoedema (9\%) (fig 1).

This article is protected by copyright. All rights reserved. 
In patients with confirmed cellulitis between 2015-2018, at least one risk factor was identified in 78 (66\%) patients. With the introduction of the new questionnaire in 2018 the proportion of patients with identified predisposing factors increased from $61 \%(195 / 320)$ to $89 \%(47 / 53)\left(\mathrm{Chi}^{2} \mathrm{p}<0.05\right)$. The most common risk factors in those with confirmed cellulitis were chronic oedema/lymphoedema in 45 (38\%) patients, trauma in 24 (20\%) patients and tinea pedis in 15 (13\%) patients (fig.2).

After introduction of the more specific questions for risk factors in 2018 the proportion of cellulitis patients identified with chronic oedema/lymphoedema rose from $34 \%(32 / 93)$ to $58 \%$ (15/26) (Chi ${ }^{2}$ $p<0.05)$ and trauma/detectable entry point detection tripled from $15 \%(14 / 93)$ to $46 \%(12 / 26)\left(\mathrm{Chi}^{2}\right.$ $p<0.05)$

\section{Discussion}

After the introduction of specific questions regarding risk factors for lower-limb cellulitis, recognition, documentation and treatment of predisposing factors increased significantly. Because of the impact of lower limb cellulitis on patients and the financial resources, prevention should be a high priority for health service interventions.

Oral penicillin $\vee 250 \mathrm{mg}$ twice daily for 12 months reduces the recurrence of cellulitis, although this protective effect is reduced to zero over three years after stopping antibiotics ${ }^{7}$. In patients with penicillin allergy Erythromycin $250 \mathrm{mg}$ BD could be used ${ }^{10}$. The treatment of predisposing dermatological conditions such as lymphoedema, venous eczema and tinea may also reduce the recurrence of cellulitis ${ }^{8}$. This analysis identified that most patients have known risk factors for cellulitis that are amenable to intervention.

This article is protected by copyright. All rights reserved. 
The number of patients with confirmed cellulitis attending this service fell from $67 \%(2007-10)^{1}$ to $57 \%$. $(2007-2015)^{8}$ to $32 \%$ in this analysis. This may be a real reduction in accurate diagnosis or represent increasing use of the service to gain a specialist opinion for patients presenting with red legs. The closure of the local community lymphoedema service for financial reasons in 2016 may also have contributed. This analysis identifies a need for targeted education, directed towards referring clinicians.

The impact of treating known risk factors on rates of lower limb cellulitis recurrence is unknown. Intervention studies in cellulitis are expensive and time consuming, so pending the outcomes of future studies, it is appropriate to seek out and treat effectively risk factors in all lower limb cellulitis. This analysis has shown that a proforma containing specific questions is more effective in identifying risk factors. Following this audit and a further literature review, the proforma has now been further updated (Figure 3).

\section{Learning Points}

- Outpatient based cellulitis services staffed by experienced dermatology nurses and doctors are an effective way of diagnosing and managing cellulitis.

- Inaccurate diagnosis of cellulitis is common in patients referred to secondary care and focused education for primary care clinicians should be prioritised.

- Risk factors for cellulitis such as chronic oedema/lymphoedema, trauma and tinea are very common and should be actively screened for and treated to reduce recurrent cellulitis.

This article is protected by copyright. All rights reserved. 


\section{Acknowledgements}

The authors received no external funding for this work.

\section{References}

1. Levell NJ, Wingfield CG, Garioch JJ. Severe lower limb cellulitis is best diagnosed by dermatologists and managed with shared care between primary and secondary care. $\mathrm{Br} \mathrm{J}$ Dermatol 2011; 164(6): 1326-1328.

2. Weng QY, Raff AB, Cohen JM, et al. Costs and Consequences Associated With Misdiagnosed Lower Extremity Cellulitis. JAMA Dermatol 2017;153(2): 141-146.

3. Department of Health and Social Care. (2016) National schedule of reference costs: the main schedule. [WWW document]. URL https://www.gov.uk/government/publications/nhsreference-costs-2015-to-2016 [accessed on 3 December 2018]

4. NHS Digital. (2017) Hospital Admitted Patient Care Activity, 2017-2018. [WWW document]. URL https://digital.nhs.uk/data-and-information/publications/statistical/hospital-admittedpatient-care-activity/2017-18\#resources [accessed on 3 December 2018].

5. Quirke M, Ayoub F, McCabe A, et al. Risk factors for nonpurulent leg cellulitis: a systematic review and meta-analysis. Br J Dermatol 2017; 177(2): 382-394.

6. Karppelin M, Siljander T, Vuopio-Varkila J, et al. Factors predisposing to acute and recurrent bacterial non-necrotizing cellulitis in hospitalized patients: a prospective case-control study. Clin Microbiol Infec 2010; 16(6): 729-34.

7. Thomas KS, Crook AM, Nunn AJ, et al. Penicillin to prevent recurrent leg cellulitis. $N$ Eng J Med 2013; 368(18): 1695-703.

8. Lee ASW, Levell NJ. Dermatology-led lower-limb cellulitis service: analysis of 1579 referrals (2007-15). Br J Dermatol 2017; 177(2): 596-597.

This article is protected by copyright. All rights reserved. 
9. Thomas KS, Brindle R, Chalmers JR, et al. Identifying priority areas for research into the diagnosis, treatment and prevention of cellulitis (erysipelas): results of a James Lind Alliance Priority Setting Partnership. Br J Dermatol 2017; 177(2): 541-543.

10. British Lymphology Society. (2016) Consensus Document on the Management of Cellulitis in Lymphoedema. [WWW document]. URL https://www.lymphoedema.org/images/pdf/CellulitisConsensus.pdf [accessed on 16 November 2018].

\section{Figure Legends}

Figure 1: The confirmed diagnoses of patients attending the cellulitis service

Figure 2: The proportion of lower limb cellulitis patients with identified risk factors

Figure 3: Risk Factors specifically asked for in lower limb cellulitis proforma

This article is protected by copyright. All rights reserved. 
Figures

Figure 1

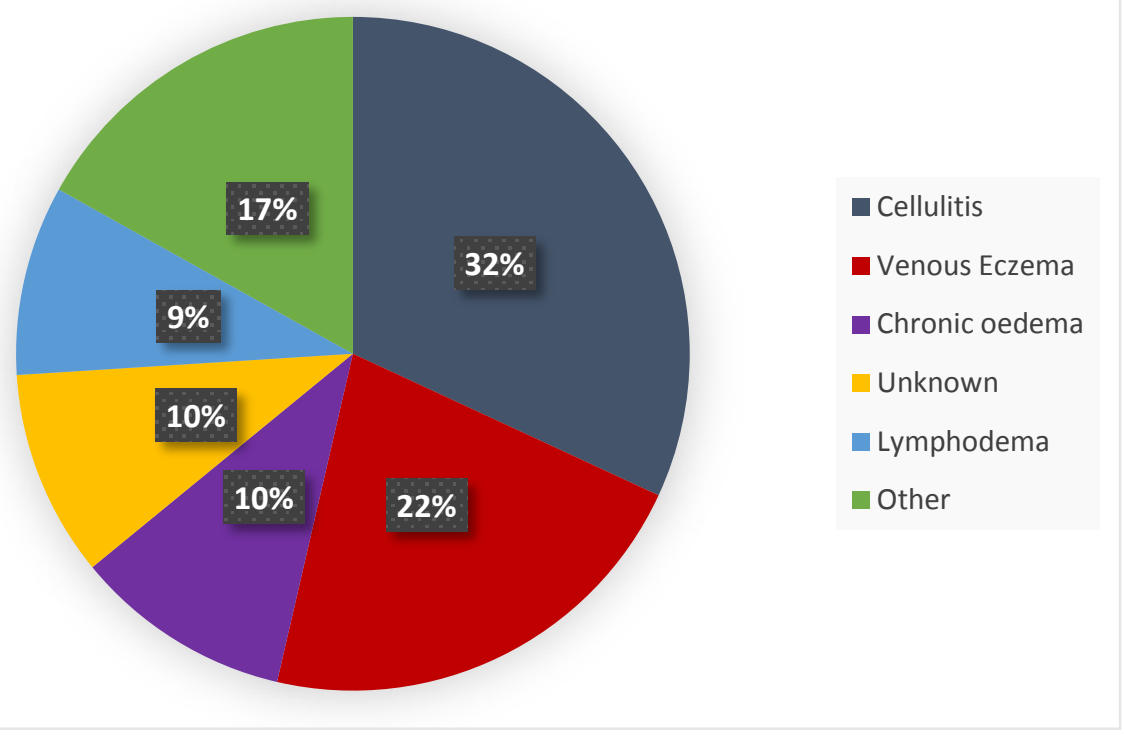

This article is protected by copyright. All rights reserved. 
Figure 2

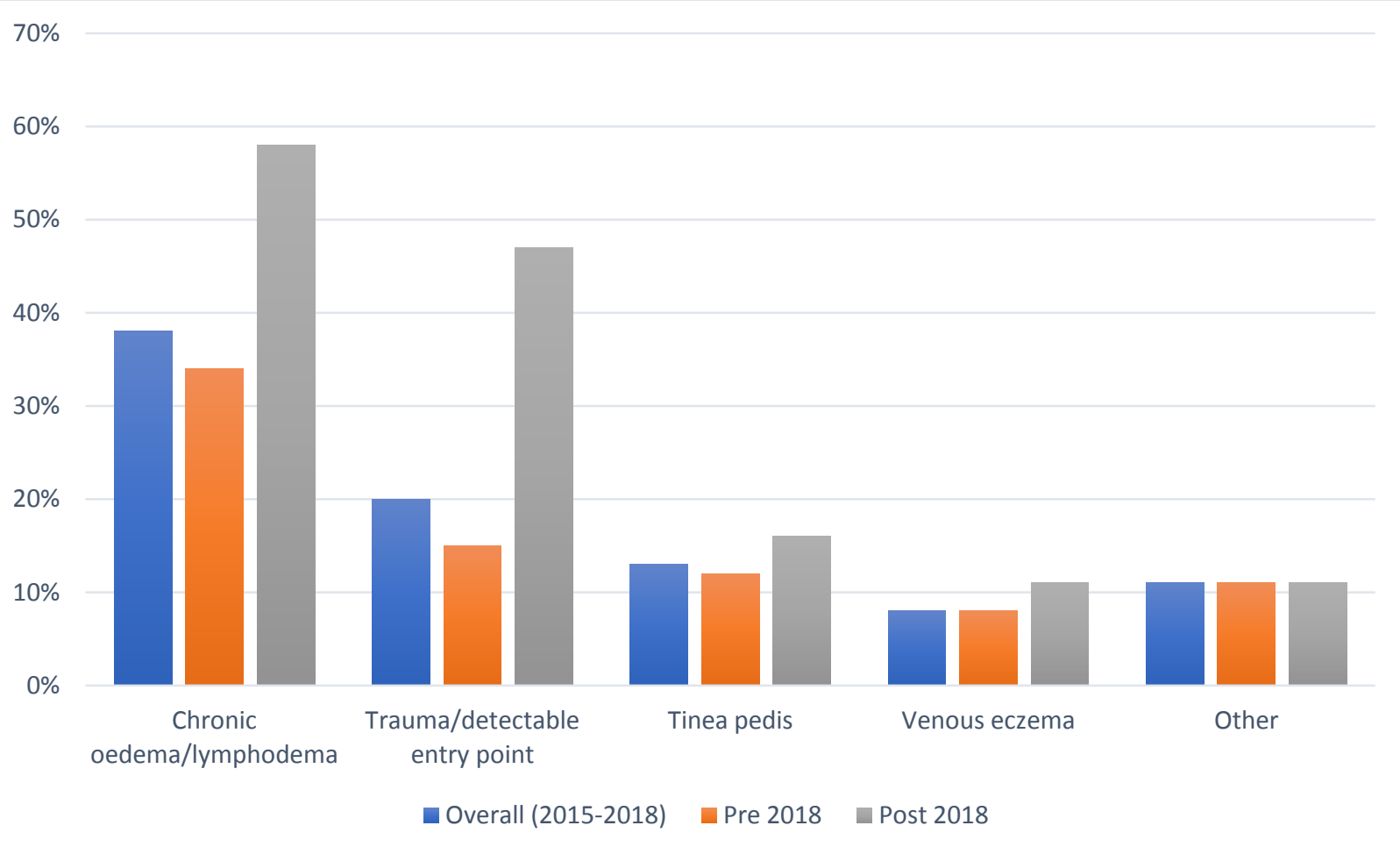

This article is protected by copyright. All rights reserved. 
Figure 3

\begin{tabular}{|c|c|c|c|}
\hline Risk Factor & $\begin{array}{c}\text { Specific questions } \\
\text { in old proforma } \\
\text { (2007-2017) }\end{array}$ & $\begin{array}{c}\text { Specific questions } \\
\text { in updated } \\
\text { proforma (January } \\
\text { 2018) }\end{array}$ & $\begin{array}{c}\text { Specific } \\
\text { questions in } \\
\text { Current } \\
\text { Proforma }\end{array}$ \\
\hline Chronic oedema/Lymphoedema $^{5}$ & $\checkmark$ & $\checkmark$ & $\checkmark$ \\
\hline Trauma/detectable entry point $^{5}$ & $\mathbf{x}$ & $\checkmark$ & $\checkmark$ \\
\hline Tinea pedis $^{5}$ & $\mathbf{x}$ & $\checkmark$ & $\checkmark$ \\
\hline Venous eczema $^{5}$ & $\mathbf{x}$ & $\checkmark$ & $\checkmark$ \\
\hline Insect bites $^{5}$ & $\mathbf{x}$ & $\checkmark$ & $\checkmark$ \\
\hline Other risk factors & $\checkmark$ & $\checkmark$ & $\checkmark$ \\
\hline Other relevant diagnoses & $\mathbf{x}$ & $\mathbf{x}$ & $\checkmark$ \\
\hline BMl >30kg/m & & $\checkmark$ & $\checkmark$ \\
\hline Smoking & & & \\
\hline
\end{tabular}

This article is protected by copyright. All rights reserved. 